\title{
Hospital Based Early Identification and Intervention for Children with Special Needs: A Conceptual Analysis
}

\author{
G. Monic Leka ${ }^{1}$ and P. Swarna Kumari ${ }^{2}$ \\ ${ }^{1}$ Research Scholar, ${ }^{2}$ Associate Professor \& Research Supervisor \\ PG \& Research Department of Rehabilitation Science, \\ Holy Cross College (Autonomous), Tiruchirappalli, Tamil Nadu, India
}

\begin{abstract}
A child's earliest years are important for the simple, but sufficient reason that they come first in a dynamic process of human development. These earliest days are filled with new stimulations and novel experiences that drive his or her cognitive, social, and physical growth. The first 3 years of life are a critical time for brain development, especially if a child is delayed or restricted in development. Early identification leads to early intervention. Intervention or lack thereof, at this stage, therefore, can significantly enhance or impair the quality of life in later years. Early intervention program is intended for infants and toddlers who have a developmental delay or disability below the age of five. Early intervention focuses on the basic developmental skills that typically develop during the first three to five years of life through a variety of therapeutic and support services which will be tailored to meet the child's individual needs. The parents/caregivers are the major contributors and performers in the Early Intervention Program. Involvement of other team members, include medical people, therapists, child development educators, social workers, and others, will depend on what the child needs. Early intervention supports the families who often experience frustration, stress, disappointment, and helplessness and helps to build a nurturing and supportive environment for the entire family. Early intervention implies for the well-being of the family and the development of the children with special needs. Keywords: Children with Special Needs, CWSN, Early identification, Early Intervention and Impairment
\end{abstract}

\section{INTRODUCTION}

Human brains triple in size during the first two years of life. The brain grows to 75 percent of its adult size by age two, and 90 percent by age three. Almost 50 percent of the brain cells will wither and die during the first few years of life (Bernhard, J.K. 2003). This process, known as neural pruning, organizes the brain and makes it more efficient. The brain learns through experiences and events, which trigger electrical impulses to the brain, establishing neural pathways. The more a pathway is used, the more established it becomes, making it less susceptible to pruning (Ball, J. 2005). A child's earliest years are important for the simple, but sufficient reason that they come first in a dynamic process of human development (National Association for the Education of Young Children. 2005). These earliest days are filled with new stimulations and novel experiences that drive his or her cognitive, social, and physical growth. The first 3 years of life are a critical time for brain development, especially if a child is delayed or restricted in development. With developmental disabilities on the rise, there is much that remains poorly understood, from cause to cure. However, there is one widely-accepted fact: early and intensive intervention can have a profound impact on the quality of life for children at risk and their families. The key is early identification. Early identification leads to early intervention. As of date, early intervention is considered to be the most important factor influencing long-term outcome in these children. Intervention or lack thereof, at this stage, therefore, can significantly enhance or impair the quality of life in later years (Hoover-Dempsey, K., Walker, J., Jones, K. and Reed, R. 2002). This is especially true for infants who are functioning or are likely to function, physically, mentally, and /or socially below par. Early intervention is a collection of therapy and support services that provide children from birth to 3 years and to 5 years of age who have disabilities, or who are at risk for developing them, the help they need to succeed later in life. It benefits children with many specific conditions (e.g., Down syndrome, cerebral palsy), in addition to children with no clear diagnosis.

Children with special educational needs are children first and have much in common with other children of the same age. There are many aspects to a child's development that make up the whole child, including - personality, the ability to communicate (verbal and non-verbal), resilience and strength, the ability to appreciate and enjoy life and the desire to learn. Each child has individual strengths, personality and experiences so particular disabilities will impact differently on individual children. A child's special educational need should not define the whole child (Derman-Sparks, L. 1994).

A mainstream class in a mainstream primary or postprimary school where the class or subject teacher has primary responsibility for the progress of all pupils in the class, including pupils with special educational needs. Additional teaching support from a learning support or resource teacher may be provided, where appropriate.

A special class in a mainstream primary or post-primary school with a lower pupil teacher ratio specified according to category of disability (Stairs A \& Bernhard, J.K., 2003). This means that classes have small numbers of pupils, for 
example, a special class for children with autistic spectrum disorder has one teacher for every six pupils. A special school with a lower pupil-teacher ratio specified according to category of disability. This means that classes have small numbers of pupils, for example a special school for children with moderate general learning disability has one teacher for every eight pupils.

A child's growth and development are followed through a partnership between parents and health care professionals.

Vision: Early identification, early intervention and holistic rehabilitation, enhance normal development and independent functioning as far as the maximum.

Goal: To enhance development, minimize the potential for developmental delay, and help families to meet the special needs of their infants and toddlers.

\section{OBJECTIVES}

1. To identify/screen children with different disabilities in the age group of 0-5 years.

2. To provide necessary intervention after proper assessment in the respective domains

3. To empower parents to enable them to deal with the special needs of their child.

4. To create awareness amongst various stakeholders for ensuring the above.

\section{WHO IS BENEFITED?}

Early intervention program is intended for infants and toddlers who have a developmental delay or disability below the age of five. However, preference would be given to children below the age of three. Some children, from birth, babies who are at high risk - significant prematurity, very low birth weight, or who are diagnosed with a specific condition like Erb's palsy or, illness, or surgery soon after being born.

For others, because of delays in development, children who relatively a routine entry into the world, but may develop more slowly than others, experience setbacks, or develop in ways that seem very different from other children.

\section{Children with}

1. Visually Impairment

2. Hearing Impairment

3. Intellectual disability (Down syndrome, DDM)

4. Learning Disability

5. Congenital Physical Deformities

6. Cerebral palsy

7. Erb's Palsy

8. Sensory motor dysfunction

9. PDD

10. ADHD

11. Speech and Language Disorder

\section{A. Focus}

Early intervention focuses on the basic developmental skills that typically develop during the first three to five years of life, such as:

1. Physical (reaching, rolling, crawling, and walking);

2. Cognitive (thinking, learning, solving problems);

3. Communication (talking, listening, understanding);

4. Social/emotional (playing, feeling secure and happy); and

5. Personal/ADL (eating, dressing).

\section{B. Therapeutic Interventions}

The Early Intervention Program offers a variety of therapeutic and support services which will be tailored to meet the child's individual needs (Ratey, John J. 2002). The services rendered as an integral part of this program may include:

1. Sensory Stimulation

2. Occupational Therapy

3. Physical Therapy

4. Speech Therapy/Pathology

5. Educational Intervention

6. Psychological Interventions/ Counselling

7. Parental Education/Training

8. Medical Intervention

\section{PROFESSIONALS TO BE INVOLVED}

The parents/caregivers are the major contributors and performers in the Early Intervention Program. Involvement of other team members, include medical people, therapists, child development educators, social workers, and others, will depend on what the child needs. Some of them, especially doctors and therapists could be consultants with specified task and could guide and train the technicians or assistants or volunteers. Depending on the patient's unique needs, the members of the rehabilitation team may include:

1. Medical people( paediatrician, Neurologist, Ortho surgeon, ENT surgeon, etc)

2. Dentist

3. Case managers/Rehabilitation Consultants/ Counsellors

4. Clinical Psychologists (Intellectual function)

5. Early Intervention Specialist/Developmental Specialist (Functional activities in all 5 areas of development)

6. Occupational therapists (Social/ Behaviour/ ADL/ Cognitive/Sensory/Higher level gross motor/ fine motor)

7. Physical therapists (Gross motor/ Physical Milestones)

8. Recreational therapists (Play/ Yoga/ Music/ Art/ Hydro therapists etc)

9. Speech-language Therapists Communication/ comprehension / attention)

10. Audiologist (auditory)

11. Vision Therapist (Vision/ attention)

12. Prosthetist/ orthotist

13. Dieticians 


\section{INDIVIDUAL INTERVENTION PLAN (IIP)}

IIP is a written document that outlines the early intervention services that the child and family will receive. In accordance to the assessments, a clear picture about the specific services the child will be receiving in the stipulated time would be mentioned. It should specify:

1. The current functional status of the child (abilities and disabilities)

2. Goals or outcomes expected

3. Various activities and games for the development in the needed areas

4. Number of sessions per day, per week, per month

5. Duration and areas of development to be concentrated

6. The specialists responsible for the sessions

7. Payment for the sessions

\section{CONCLUSION}

Ultimately, early intervention services improve skills and outcomes, increase school readiness, enable families to develop strategies and obtain resources needed for successful family functioning, encourages documentation of important early events and exposures. According to research, some children risk missing some of the most important learning and developmental milestones due to conditions noticed at birth, special needs, or developmental delays which occur in the early years. Early intervention helps these children to proceed on a path to make the most of abilities and skills developed during the early years. Early intervention supports the families who often experience frustration, stress, disappointment, and helplessness and helps to build a nurturing and supportive environment for the entire family. Early intervention implies for the well-being of the family and the development of the children with special needs.

\section{REFERENCES}

[1] Ball, J. (2005). Early childhood care and development programs as hook and hub for inter-sectoral service delivery in First Nations communities. Journal of Aboriginal Health, 1(2), 36-50.

[2] Bernhard, J. K. (2003). Towards a $21^{\text {st }}$ century developmental theory: Principles to account for diversity in children's lives. Race, Gender, and Class, 9(4), 45-60.

[3] Derman-Sparks, L. (1994). Empowering children to create a caring culture in a world of differences. Childhood Education, 70(2), 66-72.

[4] Hoover-Dempsey, K. \& Sandler, H. (1997). Why do parents become involved in their children's education? Review of Educational Research, 67, 3-42.

[5] Hoover-Dempsey, K., Walker, J., Jones, K. \& Reed, R. (2002). Teachers Involving Parents (TIP): Results of an in-service teacher education program for enhancing parental involvement. Teaching and Teacher Education, 18, 843-867.

[6] National Association for the Education of Young Children. (2005). Accreditation criteria and procedures of the National Academy of Early Childhood Programs (rev. ed.).Washington: NAEYC.

[7] Ratey, John J., (2002), A User's Guide to the Brain, NY: Vintage Books, 23.

[8] Stairs, A. \& Bernhard, J. K. (2003). Considerations for evaluating good child care in Canadian Aboriginal early childhood settings. Mc Gill Journal of Education, 37(3), 309-330. 